\title{
Use of pedometer and Internet-mediated walking program in patients with chronic obstructive pulmonary disease
}

\author{
Marilyn L. Moy, MD, MSc; ${ }^{1-4 *}$ Adrienne W. Janney, MSI; ${ }^{5}$ Huong Q. Nguyen, PhD, RN; ${ }^{6}$ Kirby R. Matthess, \\ $\mathrm{BS}^{2,4}$ Miriam Cohen, MSN; ${ }^{7}$ Eric Garshick, MD, MOH; ${ }^{2,4,8}$ Caroline R. Richardson, MD $^{5,9}$ \\ ${ }^{1}$ Rehabilitation Research and Development Service, Veterans Health Administration, Department of Veteran Affairs \\ (VA), Washington, DC; ${ }^{2}$ Pulmonary and Critical Care Medicine Section, VA Boston Healthcare System, Boston, MA; \\ ${ }^{3}$ Division of Pulmonary and Critical Care Medicine, Department of Medicine, Brigham and Women's Hospital, Boston, \\ MA; ${ }^{4}$ Harvard Medical School, Boston, MA; ${ }^{5}$ Department of Family Medicine, University of Michigan Medical \\ School; ${ }^{6}$ University of Washington, Seattle, WA; ${ }^{7}$ VA, New York Harbor, Brooklyn, NY; ${ }^{8}$ Channing Laboratory, Depart- \\ ment of Medicine, Brigham and Women's Hospital, Boston, MA; ${ }^{9}$ Ann Arbor VA Medical Center, Ann Arbor, MI
}

\begin{abstract}
We evaluated an Internet-mediated, pedometerbased program to promote walking in chronic obstructive pulmonary disease (COPD). First, we assessed the accuracy of the Omron HJ-720ITC pedometer (OMRON Healthcare, Inc; Bannockburn, Illinois) in 51 persons with COPD. The Bland-Altman plot showed a median difference of 3 steps (5th and 95th quintiles, -8.0 and 145.0 , respectively). We calculated percent difference $=([$ manual - Omron step counts $] /$ manual step counts $) \times$ 100. Variability in percent difference occurred at the lowest usual walking speeds. At speeds $\leq 0.94 \mathrm{~m} / \mathrm{s}$, the mean $+/$ - standard deviation percent difference was $14+/-26 \%$. Nevertheless, the Omron captured $>80 \%$ of the manual step counts in 20 of the 23 persons with walking speed $\leq 0.94 \mathrm{~m} / \mathrm{s}$. Second, we examined step counts in 24 persons with COPD who used the Omron and an Internet-mediated, 16-week walking program. At baseline, participants with COPD walked an average of $3429+/-1502$ steps per day. Sixteen participants completed the program with an average increase in daily step count of $988+/-1048$ steps ( $p=$ 0.002). The Omron is accurate in persons with COPD with usual walking speeds $>0.94 \mathrm{~m} / \mathrm{s}$. Accuracy is more variable at lower speeds, but the Omron captures more than $80 \%$ of manual step counts in most persons. In this preliminary study, an Internetmediated walking program using the Omron significantly increased step counts in COPD.
\end{abstract}

Key words: accuracy, ambulation, COPD, exercise capacity, HRQL, Internet, intervention, pedometer, physical activity, pulmonary rehabilitation, walking.

\section{INTRODUCTION}

In persons with chronic obstructive pulmonary disease (COPD), exercise capacity-measured by clinicbased tests such as maximum oxygen consumption during a cardiopulmonary exercise test or maximum distance walked on a 6-minute walk test (6MWT) — significantly predicts mortality, independent of forced expiratory volume in $1 \mathrm{~s}\left(\mathrm{FEV}_{1}\right)$ [1-2]. In addition to exercise capacity, physical activity and, specifically, walking measured by daily step counts are significantly reduced in persons with

\footnotetext{
Abbreviations: $6 \mathrm{MWT}=6$-minute walk test, $\mathrm{BMI}=$ body mass index, $\mathrm{CAD}=$ coronary artery disease, $\mathrm{COPD}=$ chronic obstructive pulmonary disease, $\mathrm{DM}=$ diabetes mellitus, $\mathrm{ER}=$ emergency room, $\mathrm{FEV}_{1}=$ forced expiratory volume in $1 \mathrm{sec}-$ ond, GOLD = Global Initiative for Chronic Obstructive Lung Disease, $\mathrm{RCT}=$ randomized controlled trial, $\mathrm{SD}=$ standard deviation, SUH $=$ Stepping Up to Health, VA = Department of Veterans Affairs.

* Address all correspondence to Marilyn L. Moy, MD, MSc; Pulmonary and Critical Care Medicine Section, VA Boston Healthcare System, 1400 VFW Parkway, Mail Code 111PI, West Roxbury, MA 02132; 857-203-6622; fax: 857-2035670. Email: marilyn.moy@va.gov

DOI:10.1682/JRRD.2009.07.0091
} 
moderate to severe COPD compared with healthy subjects [3-4]. Level of free-living physical activity, assessed by questionnaire or accelerometers, relates to health outcomes in COPD. Adjusting for $\mathrm{FEV}_{1}$ percent predicted, persons with COPD who are more physically active reduce their risk of hospital admissions for COPD and respiratory mortality [5]. Reduced walking measured as daily step counts in persons with COPD is associated with higher levels of circulating markers of systemic inflammation, such as C-reactive protein and fibrinogen, inflammatory markers associated with greater all-cause and cardiovascular mortality [6].

These results suggest that efforts to increase daily step counts may positively impact health-related outcomes in COPD. Total walking step count has been shown to be closely related to overall daily activity in persons with COPD [7]. The literature suggests that all forms of walking, from walking as part of functional community mobility to sustained cardiovascular exercise, are beneficial in COPD. However, little research has assessed methods for promoting walking in persons with COPD.

The Internet may be an effective platform for implementing widely accessible, home-based walking programs for persons with COPD. Approximately 71 percent of adult Americans use the Internet, with older users aged 50 to 64 years as well represented online as younger users [8-9]. Eighteen percent of consumers, aged 65 and older, conducted online health searches in 2007, compared with seven percent in 2001 [10]. Two studies that used the Internet for dyspnea self-management in subjects (mean age 69 years) with COPD showed that 34 percent of subjects used the Internet for an average of 11.7 hours a week [11-12]. In addition, programs based on pedometer feedback have been shown to increase walking in the general population and in persons with chronic medical conditions [13-14]. Combining the use of a Web site and the Omron HJ-720ITC pedometer (OMRON Healthcare, Inc; Bannockburn, Illinois), the Stepping Up to Health (SUH) program (1) sets walking goals, (2) provides feedback and motivational messages, and (3) monitors walking progress. SUH has been shown to increase daily step counts in individuals with type 2 diabetes mellitus (DM) [15]. We do not know if persons with COPD, who generally have slower walking speeds and lower baseline levels of physical activity than persons with other chronic medical conditions, would benefit from such a program.

We conducted two studies to begin our examination of the feasibility, safety, and efficacy of an Internet-mediated, pedometer-based walking program in persons with COPD. First, we assessed the accuracy of the Omron in the laboratory setting in persons with COPD. Second, we performed a post hoc analysis of step-count data for a subset of persons with self-reported obstructive lung disease who participated in a randomized controlled trial (RCT) that studied the Omron and the SUH Internet-mediated walking program.

\section{METHODS}

\section{Omron HJ-720ITC Enhanced Pedometer}

The Omron HJ-720ITC enhanced pedometer (Figure 1), used in both studies, costs approximately \$30, is lightweight (35 g), and has an embedded universal serial bus (USB) port that allows interface with the Internet. A lithium battery lasts approximately 6 months. The pedometer provides continuous step-count feedback and allows the user to review step-count history for the previous 7 days. It stores 42 days of time-stamped step-count data that can be uploaded via a USB cable to a computer so that the data can be graphically displayed. The Omron has been shown to be accurate and reliable in healthy and overweight subjects [16-17], but its accuracy has not been assessed in persons with COPD.

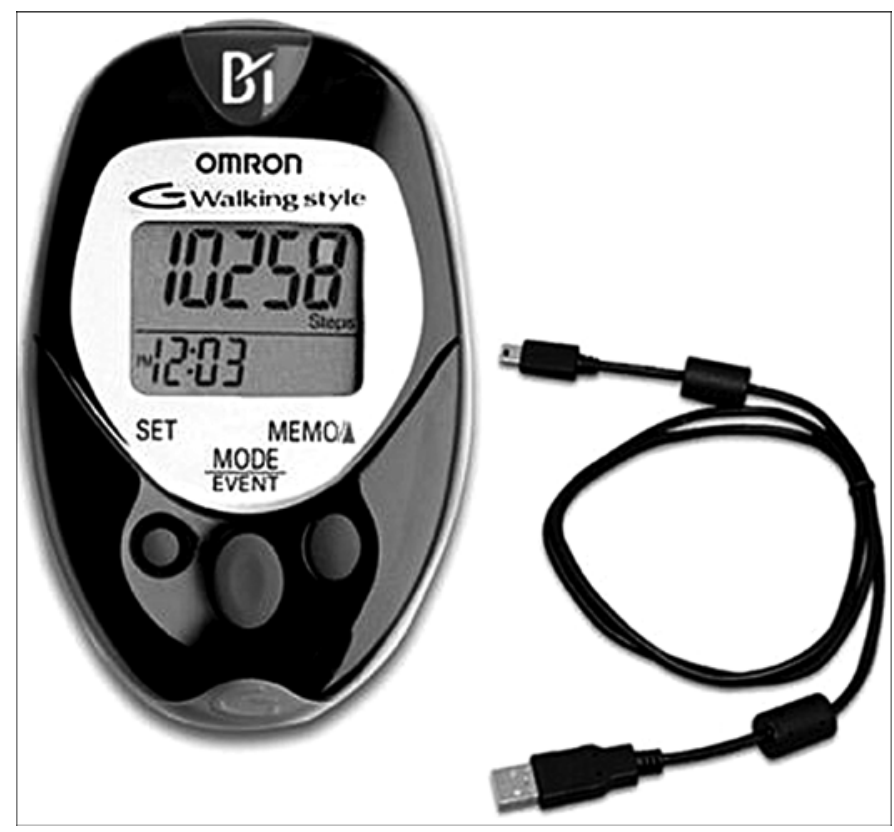

Figure 1.

Omron HJ-720 ITC enhanced pedometer. 


\section{Study 1: Accuracy of Omron in Persons with COPD}

Fifty-one subjects with COPD, aged $>40$ years, $\mathrm{FEV}_{1} /$ forced vital capacity $<0.70$, and with a smoking history of $>10$ pack-years, were enrolled from the pulmonary clinic at the Department of Veterans Affairs (VA) Boston Healthcare System. Subjects were excluded if they had had a COPD exacerbation, defined as worsening pulmonary symptoms requiring antibiotics or systemic corticosteroids, in the previous month. Medical records were reviewed for diagnoses that could affect walking, such as osteoarthritis, hip or knee replacement, chronic low back pain, type 2 DM, coronary artery disease (CAD), and overweight (body mass index $[\mathrm{BMI}] \geq 25$ ). Participants wore the Omron clipped to the waistband on the right lateral side and walked a level $800 \mathrm{ft}$ course in a hospital corridor. Subjects were instructed to walk at their usual walking speeds and, specifically, not to walk fast. Subjects could take as long as they needed to complete the course; they were allowed to rest during the walk. To mimic usual walking during the test, subjects who used oxygen carried or pushed their oxygen tanks as they would typically do at home.

One investigator counted every step taken by the right foot using a manual tally counter, which was multiplied by two for the total manual step count. The investigator was blinded to the Omron step counts, which were downloaded after the walk was completed. Usual walking speeds were calculated with the measured time to walk the course. The Bland-Altman plot compared the Omron step counts with the manual step counts. We calculated percent difference $=[($ manual - Omron step counts $) /$ manual step counts] $\times 100$.

\section{Study 2: Use of Internet-Mediated Pedometer-Based Walking Program in Persons with COPD}

This post hoc analysis examined data from a subset of participants, enrolled in an RCT that studied the Omron and the SUH Internet-mediated walking program from January to June 2008, who self-reported emphysema, asthma, or bronchitis. All 324 participants who participated in the RCT were adults with at least one of three conditions: (1) type $2 \mathrm{DM}$, (2) CAD, or (3) BMI $\geq 25$. Eligibility screening and informed consent occurred online. The Omron was worn during all awake hours for a 7-day baseline period when the pedometer display was covered with a sticker and subjects did not receive any step-count feedback, step-count goals, or tailored messages designed to promote walking. After this period, participants were instructed to remove the sticker and upload the step-count data to the study server. Participants completed an online survey assessing medical history, health behaviors, social support, and attitudes about walking. Participants who completed the baseline data collection entered the intervention phase. In the RCT, participants were randomized to one of two groups: communication with other subjects using an online message board or no communication. All subjects used the Omron and the SUH walking program. Primary analysis showed that subjects with access to the online community did not have significantly different step counts compared with those without access [18]. Therefore, results presented here consider all participants as a single group.

\section{Intervention}

The SUH walking intervention is based on selfregulation theory, which emphasizes an iterative, rational process of behavior change in which an individual learns from successes and failures to develop effective behavioral strategies to achieve a goal [19-20] (Figure 2). SUH supports the cycle of self-regulation to promote walking by providing (1) accurate assessment and feedback of step counts, (2) individualized step-count goals, and (3) tailored motivational messages. Participants were instructed to wear their pedometers every day while awake for 16 weeks and upload step-count data at least once a week to the study server using their home computers.

\section{Step-Count Feedback}

Participants received continuous step-count feedback by looking at the digital display on the Omron face. Participants could also view graphical displays and text summaries of their step-count history on their study Web page (Figure 3).

\section{Goal Setting}

The program calculated an individualized daily stepcount goal each week, adding an increment of 800 steps to the average of the most recently uploaded 7 days of stepcount data. The 800-step increment was based on feedback from participants with type $2 \mathrm{DM}$ in a pilot study of the SUH intervention [15]. Each subject received a weekly email with the week's step-count goal, which was also prominently displayed on his or her Web study page (Figure 3). 


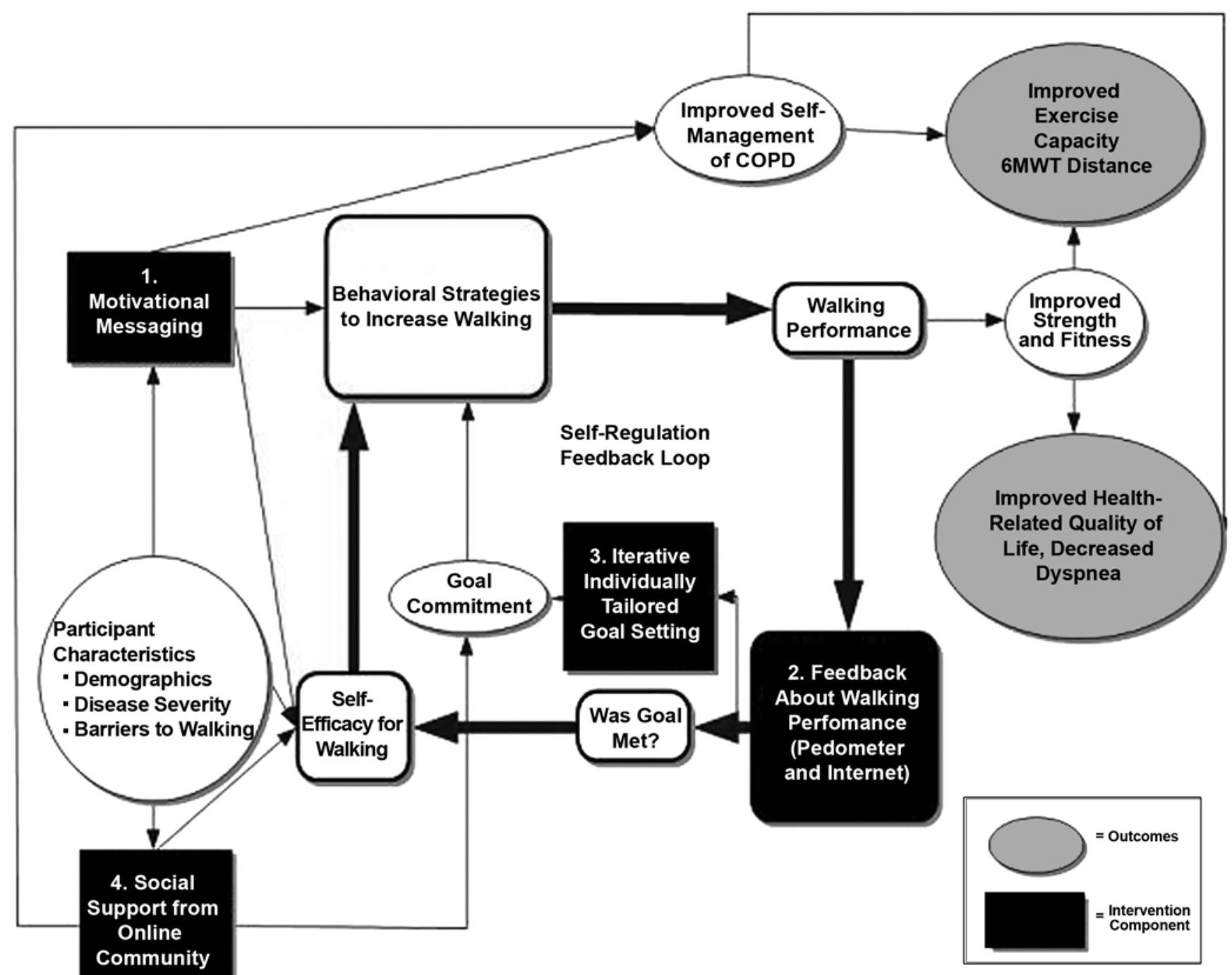

Figure 2.

Conceptual model for Stepping Up to Health, an Internet-mediated walking program. COPD = chronic obstructive pulmonary disease, 6MWT = 6-minute walk test.

\section{Tailored Motivational Messages}

The study Web site displayed individually tailored motivational messages using responses from the detailed baseline survey. Motivational messages, updated weekly, addressed barriers to walking as well as behavioral strategies to increase walking. The content of the messages was not specifically targeted for individuals with COPD.

\section{Participants}

In this post hoc analysis, study participants in the RCT aged $>40$ years were included $(n=266)$. The subset of participants aged $>40$ years who answered yes to the question of whether they have emphysema, asthma, or bronchitis, and who were either current or former smokers, was defined as having a diagnosis of COPD $(n=24)$.

\section{Statistical Analysis}

Baseline and change in average daily step counts were compared between and within groups, with and without COPD, with the use of $t$-tests. Step counts for any 24-hour period were analyzed if the total step counts were $>100$ steps a day and the Omron had been worn for at least 8 hours. Average baseline step count was calculated from pedometer data for at least 5 of the 7 days of 

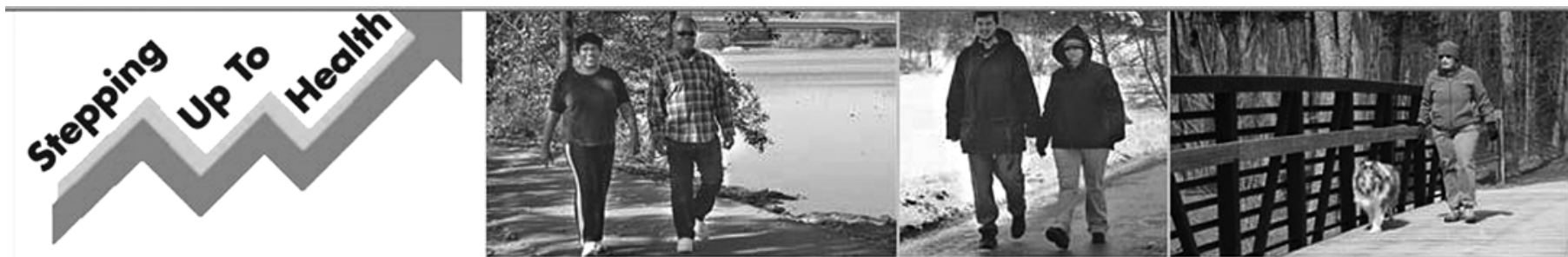

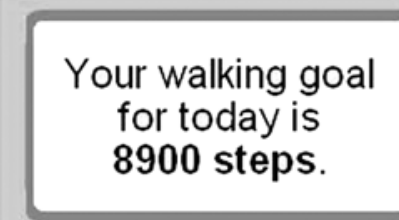

\section{Caroline}

Home

Get started

Download software

Groups

Today's tip

Get motivated

Group Graph

My unread

Talk to other

participants

Log out
Learn about your profile.

\section{Your progress}

For the week of April 20, 2008 to April 26, 2008 , you met your walking goal of 9600 steps on 3 of 7 days. Your average daily step count for the week was 9823 steps.

Use the calendar on the right to see a different week on the graph. Click on a bar on the graph to see the day's detail.

\begin{tabular}{|cccccccc|}
\hline 1 & \multicolumn{3}{c}{ April } & \multicolumn{3}{c|}{2008} & \\
\hline $\mathrm{S}$ & $\mathrm{M}$ & $\mathrm{T}$ & $\mathrm{W}$ & $\mathrm{T}$ & $\mathrm{F}$ & $\mathrm{S}$ \\
& & 1 & 2 & 3 & 4 & 5 \\
6 & 7 & 8 & 9 & 10 & 11 & 12 \\
13 & 14 & 15 & 16 & 17 & 18 & 19 \\
\hline 20 & 21 & 22 & 23 & 24 & 25 & 26 \\
\hline 27 & 28 & 29 & 30 & & & \\
\hline
\end{tabular}

\begin{tabular}{l|l|l} 
Week and day & Step types \\
\hline
\end{tabular}

Steps for the week of April 20, 2008

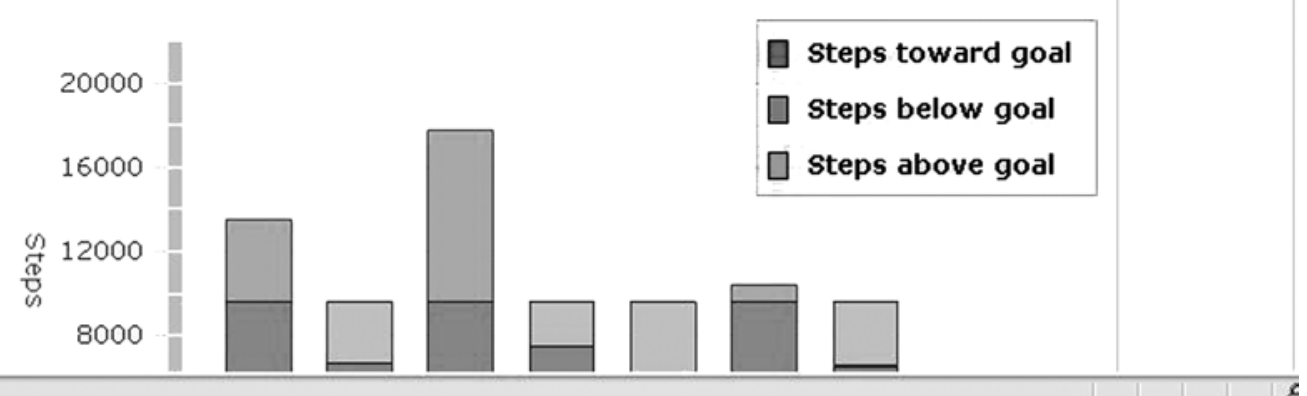

Figure 3.

Example of Stepping Up to Health (an Internet-mediated walking program) personalized Web study page.

the baseline period. Average end-of-study step count was calculated from data for at least 20 of the last 30 days of the 16-week study period. The results of a completer's analysis that included participants who had valid end-ofstudy step-count data and an intention-to-treat analysis that included all participants who had valid baseline stepcount data are presented. Baseline step counts rather than last recorded step counts were carried forward because we assumed that those who did not complete the study returned to their baseline level of walking. Linear regression analysis estimated the differences in change in step counts between those participants with and without COPD, using end-of-study step counts as the outcome measure and adjusting for age, sex, baseline step count, $\mathrm{DM}, \mathrm{CAD}$, and BMI.

\section{RESULTS}

\section{Study 1: Accuracy of Omron in Persons with COPD}

The 49 men and 2 women, with a mean age \pm standard deviation (SD) of $70 \pm 8$ years, had mean $\mathrm{FEV}_{1} 1.39 \pm$ $0.74 \mathrm{~L}$ (48\% $\pm 23 \%$ of predicted values). They represented all four Global Initiative for Chronic Obstructive Lung Disease (GOLD) stages of COPD severity, with 5 subjects (10\%) with mild GOLD stage I, 20 subjects (39\%) with moderate GOLD stage II, 11 subjects (22\%) with severe 
GOLD stage III, and 15 subjects (29\%) with very severe GOLD stage IV [21]. Twenty-one subjects (41\%) had a diagnosis of osteoarthritis, hip or knee replacements, or chronic low back pain. Thirteen subjects (25\%) had DM, fifteen (29\%) had CAD, and thirty five (69\%) had BMI $\geq 25$. No subject used a walking aid, and 19 of the 51 subjects (37\%) used supplemental oxygen during the walk.

The Bland-Altman plot shows a median difference of 3.0 steps, and 5th and 95th quantiles of -8.0 and 145.0, respectively (Figure 4). The median difference is close to 0 , reflecting the accuracy of the monitor in a laboratory setting. The lower limit of -8.0 shows that the monitor seldom overestimates step counts, while the upper limit of 145.0 shows that the monitor may underestimate step counts.

The Bland-Altman plot also shows that the distribution of the difference is skewed, predominantly by the results of five subjects. We plotted percent difference [(manual - Omron)/manual] $\times 100$ by usual walking speed, and subjects with the greatest percent difference had the lowest walking speeds (Figure 5). We examined subjects who walked at $>0.94 \mathrm{~m} / \mathrm{s}$ or $3,380 \mathrm{~m} / \mathrm{h}$ (the average walking speed for the group) and those who walked at $\leq 0.94 \mathrm{~m} / \mathrm{s}$. At usual walking speed $>0.94 \mathrm{~m} / \mathrm{s}(n=28)$, the mean percent difference was $1.7 \pm 6.9$. At usual walking

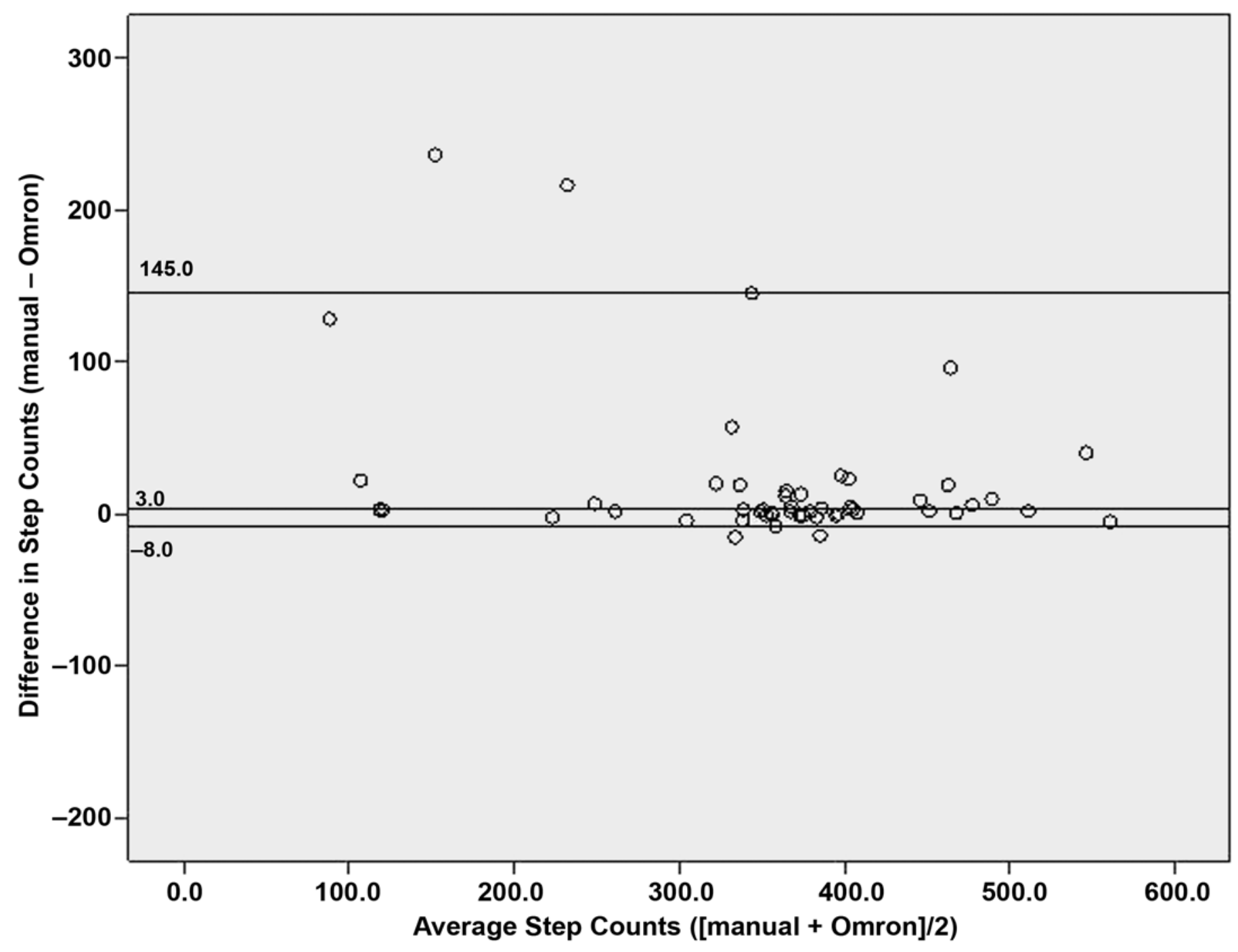

Figure 4.

Bland-Altman plot showing accuracy of Omron in persons with chronic obstructive pulmonary disease. Reference lines represent median and 5th and 95th quantiles. 
speed $\leq 0.94 \mathrm{~m} / \mathrm{s}(n=23)$, variability in the difference was greater, with mean percent difference of $14 \pm 26$ percent. Nevertheless, the Omron captured $>80$ percent of manual step counts in 20 of the 23 subjects (87\%) and captured $>90$ percent of manual step counts in 17 of the 23 subjects (74\%).

\section{Study 2: Use of Internet-Mediated Pedometer-Based Walking Program in Persons with COPD}

Of the 266 participants, aged $>40$ years, 24 were former or current smokers and reported emphysema, asthma, or bronchitis, meeting our definition of having concomitant COPD (Table 1). Among those with COPD, baseline average daily step count was 3,429 $\pm 1,502$, range 642 to 7,166 steps. Of the 24, 16 participants with COPD (67\%) completed the 16-week walking program and uploaded valid baseline and end-of-study step-count data. This completion rate is lower than, but not significantly different from, the completion rate of 78 percent among participants without COPD. For the 16 completers, the increase in step counts was $988 \pm 1,048$ ( $p=$ 0.002 ) steps per day, equivalent to about $0.80 \mathrm{~km}$. In the intention-to-treat analysis, the average daily increase in step counts was $658 \pm 971$ ( $p=0.003)$, or an increase of

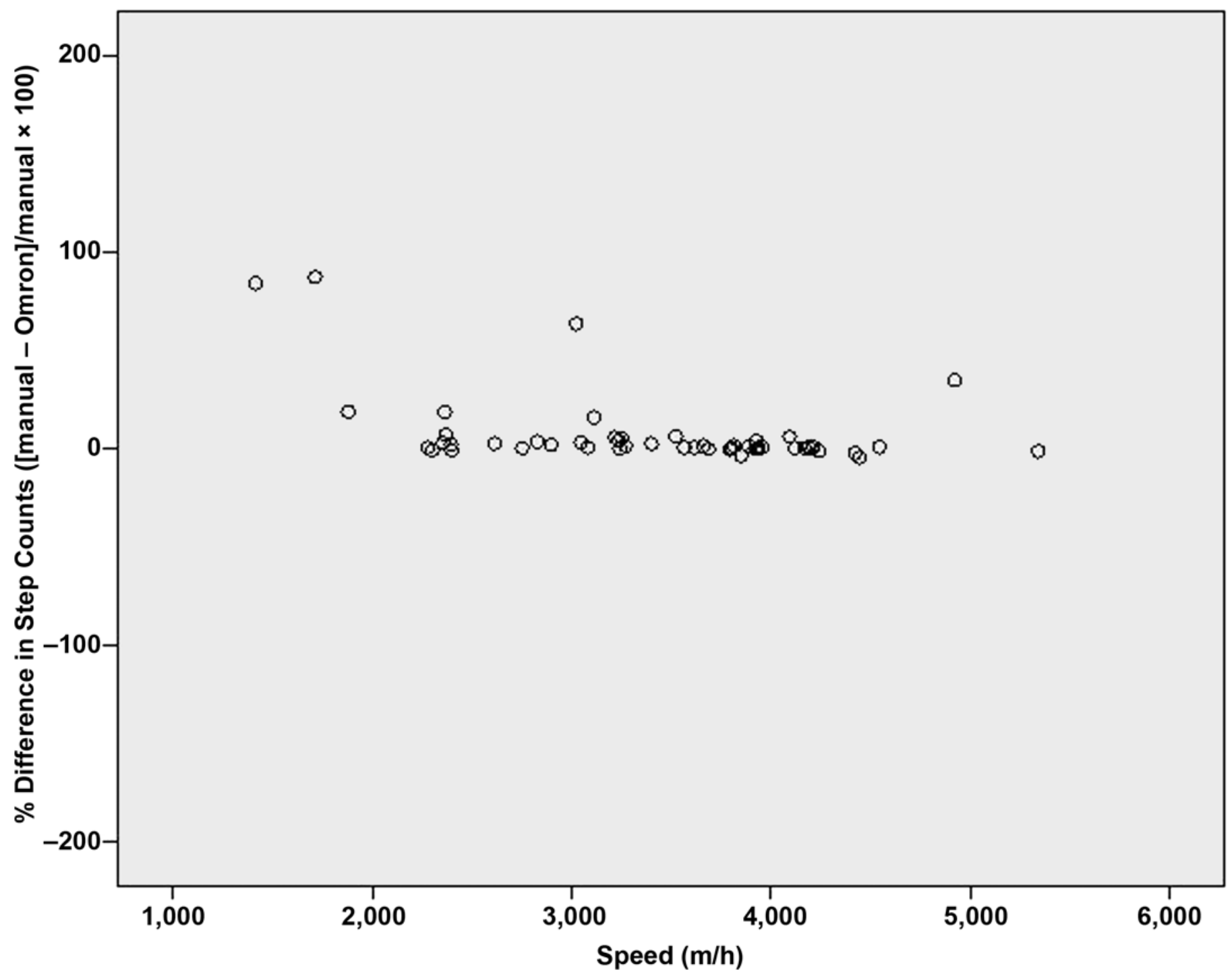

Figure 5.

Plot of percent difference by usual walking speed in persons with chronic obstructive pulmonary disease using Omron pedometer. 
JRRD, Volume 47, Number 5, 2010

Table 1.

Demographics and baseline characteristics for Stepping Up to Health participants aged $\geq 40 \mathrm{yr}$.

\begin{tabular}{lcc}
\multicolumn{1}{c}{ Characteristic } & COPD & No COPD \\
\hline$n$ (\% frequency) & $24(9)$ & $242(91)$ \\
Age; mean \pm SD (yr) & $56 \pm 7$ & $56 \pm 9$ \\
Sex, $n$ (\%) & $13(54)$ & $90(37)$ \\
$\quad$ Male & $11(46)$ & $152(63)$ \\
Female & $0(0)$ & $3(1)$ \\
Hispanic, $n$ (\%) & & \\
Race, $n$ (\%) & $18(75)$ & $213(88)$ \\
Caucasian & $4(17)$ & $11(5)$ \\
African American & $0(0)$ & $6(2)$ \\
Asian & $0(0)$ & $2(1)$ \\
American Indian & $2(8)$ & $2(1)$ \\
Other & & \\
BMI & $35 \pm 7$ & $32 \pm 6$ \\
Mean \pm SD & $24(100)$ & $239(99)$ \\
BMI $\geq 25$ (overweight), $n(\%)$ & $16(67)$ & $141(58)$ \\
BMI $\geq 30$ (obese), $n$ (\%) & $6(25)$ & $34(14)$ \\
Coronary Artery Disease, $n$ (\%) & $10(42)$ & $54(22)$ \\
Diabetes Mellitus, Type 2, $n(\%)$ & $12(50)$ & $99(42)$ \\
Used Pedometer in Past, $n(\%)$ & & \\
Internet Proficiency, $n$ (\%) & $1(4.2)$ & $81(3.4)$ \\
Limited & $3(12.5)$ & $22(9.4)$ \\
Basic & $8(33.3)$ & $84(35.7)$ \\
Moderate & $8(33.3)$ & $90(38.2)$ \\
Advanced & & \\
Expert & & \\
\hline BMI = body mass index, COPD = chronic obstructive pulmonary disease, \\
SD = standard deviation. & & \\
\hline \hline
\end{tabular}

about $0.54 \mathrm{~km}$. Both the average baseline step counts and the average increase in step counts after the intervention were lower for those with COPD than for those without COPD (Table 2). Among the 205 completers, adjusting for age, sex, baseline step count, DM, CAD, and BMI, those with COPD increased average daily step counts by 1,553 fewer steps than those without COPD $(p=0.02)$. No serious adverse events occurred among the participants with concomitant COPD.

\section{DISCUSSION}

The Omron is highly accurate in detecting step counts in persons with COPD and usual walking speed $>0.94 \mathrm{~m} / \mathrm{s}$. Although accuracy is more variable at usual walking speeds $\leq 0.94 \mathrm{~m} / \mathrm{s}$, the Omron captures over 80 percent of manual step counts in 87 percent of cases.
Our data demonstrate that for the vast majority of persons with COPD, the Omron is an accurate device that allows interface with an Internet-mediated walking program. In this preliminary study, SUH, which provides feedback, individualized goals, and motivational messages, significantly increased step counts in persons with COPD. We also demonstrate that using the Internet to implement a walking program is feasible, with over three-quarters of the participants, with and without COPD, reporting at least moderate proficiency in using the Internet. These preliminary but promising data suggest that Internetmediated interventions to promote walking could significantly increase step counts and potentially improve health-related outcomes in persons with COPD.

For the development of a home-based exercise program, the required methodology to monitor the exercise performed must be accurate, simple, and inexpensive. The three devices most commonly used to date to measure step counts in COPD by other investigators are the Tritrac R3D (newer version is RT3) (Reining International, Ltd; Madison, Wisconsin), the Dynaport Activity Monitor (McRoberts BV; The Hague, the Netherlands), and the SenseWear Armband (BodyMedia, Inc; Pittsburgh, Pennsylvania). However, limitations such as lack of specificity, requirement for correct placement on the body, expense, and inability to connect with a computer prohibit their implementation on a large scale for homebased exercise programs [22-26]. In contrast, the lightweight, easy-to-use Omron is inexpensive, provides immediate feedback, and interfaces with the Internet. Moreover, since persons with COPD have low walking speeds and walking speed has been shown to predict accuracy of devices [27-28], home-based exercise programs must use devices that have been validated at low walking speeds. Comparison of device step counts to manual step counts, specifically at low walking speeds, has yet to be determined for the Tritrac R3D, the Dynaport Activity Monitor, and the SenseWear Armband in persons with COPD. We have characterized the performance of the Omron in persons with COPD and showed that the Omron is accurate in detecting step counts in the majority of persons with COPD.

Previous work has demonstrated that Internetmediated, pedometer-based walking programs can be safe for individuals with chronic medical conditions $[15,29]$. We show that persons with COPD are no more likely to experience adverse events than those without COPD when participating in such a program. In this study, we tracked adverse events closely to quantify and 
Table 2.

Average daily step counts for completers of 16-week Stepping Up to Health program.

\begin{tabular}{lccc}
\hline \multicolumn{1}{c}{ Variable } & COPD & No COPD & $\begin{array}{c}p \text {-Value for Between-Group } \\
\text { Comparison }\end{array}$ \\
\hline Program Completers $(n)$ & 16 & 189 & NA \\
Average Daily Baseline Steps & $3,596 \pm 1,532$ & $4,468 \pm 1,935$ & 0.08 \\
Average Daily End Steps & $4,584 \pm 1,586$ & $7,129 \pm 3,147$ & 0.002 \\
Change in Steps & $988 \pm 1,048$ & $2,660 \pm 2,582$ & 0.01 \\
$p$-Value for Pre-/Postcomparison & 0.002 & $<0.001$ & NA \\
\hline COPD = chronic obstructive pulmonary disease, NA $=$ not applicable. & & \\
\hline
\end{tabular}

describe potential negative effects of starting an Internetmediated walking program. Seven serious adverse events occurred among all 324 participants over the 16 weeks of intervention. One subject slipped on ice and broke a leg while taking a walk. One subject had a hypoglycemic event resulting in a fall and an emergency room (ER) visit. Five subjects experienced chest pain, shortness of breath, or an exacerbation of congestive heart failure that resulted in ER visits. No deaths were reported.

Among all 324 participants, 102 minor adverse events occurred, with musculoskeletal injuries being the most common. Starting an exercise program is known to be associated with muscle aches and other related problems like plantar fasciitis, many of which can be resolved with proper shoes, continued activity, weight loss, and improved fitness. For our purposes, all these symptoms were counted as adverse events, contributing to the 102 minor adverse events. In addition, the number of adverse events is partly a function of the participants' health status. In this cohort of overweight or obese participants with multiple chronic medical conditions, the risk of musculoskeletal injuries and other adverse events is higher than in the general population. The number of minor discomforts and injuries is not unusual for sedentary individuals who are either overweight and/or have chronic disease when beginning a walking program.

Our studies have several strengths. The accuracy of the Omron was assessed in the specific population in whom it was being used for the SUH walking program. The SUH intervention provided real-life information on the feasibility, safety, and efficacy of its automated use in persons with COPD. However, several limitations deserve discussion. First, Omron accuracy was variable in persons who walked at the slowest speeds and Omron accuracy was not verified for each participant in the SUH program. The reasons for greater variability in the accuracy of step-count recording at the lower walking speeds are not clear but are likely related to the limits of the degree of motion detectable by the piezoelectric strain gauge in the Omron. We expect that most persons with COPD, in whom we want to promote walking with an Internet-mediated walking program like $\mathrm{SUH}$, will be walking for exercise with speeds $>1 \mathrm{~m} / \mathrm{s}$. These purposeful steps from walking as exercise are the most important to capture for the SUH intervention. We acknowledge that confirming accuracy of a pedometer in a controlled laboratory setting does not ensure accuracy in a field setting. Therefore, step counts may have been inaccurate in some of the SUH participants. However, for the slowest walkers, the observed step counts would likely be lower than the true step counts and this error would tend to bias the estimate of change in average daily step counts toward the null hypothesis (no increase in average daily step counts).

Second, persons enrolled in the SUH intervention did not have COPD confirmed by spirometry. The subjects classified as having COPD had answered "yes" to the question of whether they had emphysema, asthma, or bronchitis. This self-report of having COPD, along with the age $>40$ years and a current or past smoking history, indicate that all subjects likely had COPD. The range of average baseline daily step counts observed was similar to those previously reported for persons with COPD $[3,7,30]$. However, the possibility exists that some persons with asthma were misclassified as having COPD. If participants with asthma increased their step counts more than participants with COPD, then our observed increase in step counts may be higher than the true increase in step counts for individuals with COPD.

Third, we acknowledge that SUH is a program aimed at increasing walking alone. SUH does not monitor intensity and is not an exercise program aimed at increasing maximum oxygen consumption. Finally, we did not measure outcomes in those participants who dropped out 
before the end of the SUH intervention. In our intentionto-treat analysis, we assumed that individuals who dropped out of the walking program returned to their baseline levels of physical activity. Most of the participants in the study were sedentary at baseline, and they did not likely become even more sedentary after dropping out. This result can be thought of as a floor effect. The impact of error in this assumption on reported outcomes is limited by the relatively low dropout rate in the study.

Future studies will need to confirm our preliminary but promising findings in a larger cohort of persons with COPD confirmed with spirometry and with a control group. In addition, future work will include adapting the current SUH program for specific use in persons with COPD. Compared with those without COPD, those with COPD had a slightly lower completion rate, although not statistically significantly different, and step counts improved to a lesser degree in response to SUH. This population would likely benefit from an intervention specifically targeted at COPD. For example, in the SUH intervention, maximal daily goals were 10,000 steps a day, which is likely to be high for participants with COPD. In addition to adapting step-count goal increments and maximum targets, creating tailored messages to address breathlessness and bronchodilator and oxygen use during walking may benefit participants with COPD.

\section{CONCLUSIONS}

The Omron is accurate in the vast majority of persons with COPD; however, it is less accurate in those persons with the slowest walking speeds. An Internet-mediated walking program using the Omron, targeting individuals with DM or CAD or who are overweight, is feasible and safe and significantly increases step counts in subjects with concomitant COPD.

\section{ACKNOWLEDGMENTS}

\author{
Author Contributions: \\ Study concept and design: M. L. Moy, H. Q. Nguyen, M. Cohen, \\ C. R. Richardson. \\ Acquisition of data: M. L. Moy, A. W. Janney, K. R. Matthess, \\ C. R. Richardson. \\ Analysis and interpretation of data: M. L. Moy, H. Q. Nguyen, \\ M. Cohen, E. Garshick, C. R. Richardson. \\ Drafting of manuscript: M. L. Moy, A. W. Janney, H. Q. Nguyen, \\ M. Cohen, E. Garshick, C. R. Richardson.
}

Critical revision of manuscript for important intellectual content: M. L. Moy, A. W. Janney, H. Q. Nguyen, M. Cohen, E. Garshick, C. R. Richardson.

Statistical analysis: M. L. Moy, A. W. Janney, M. Cohen, E. Garshick, C. R. Richardson.

Obtaining funding: M. L. Moy, C. R. Richardson.

Technical support: A. W. Janney, K. R. Matthess.

Study supervision: M. L. Moy, C. R. Richardson.

Financial Disclosures: The authors have declared that no competing interests exist. This study was initiated by the investigators who received a research discount on pedometers from OMRON Healthcare and no other commercial financial support. The results of the present study do not constitute endorsement of the product by the authors. OMRON Healthcare had no involvement in the study design, the collection, analysis, and interpretation of data; in the writing of the report; or in the decision to submit the paper for publication.

Funding/Support: This material was based on work supported in part by the VA, Veterans Health Administration, Rehabilitation Research and Development Service, through a VA Career Development Award to Dr. Moy. Awarded to Dr. Richardson was the Robert Wood Johnson Foundation (grant 57408); the National Heart, Blood, and Lung Institute (grant 1 K23 HL075098); the Center for Health Communications Research-University of Michigan; and the Michigan Diabetes Research and Training Center (grant 5 P60 DK020572). The National Institutes of Health, Eunice Kennedy Shriver National Institute of Child Health and Human Development, grant RO1 HD42141was awarded to Dr. Garshick.

Institutional Review: The first study protocol was approved by the VA Boston Healthcare System Committee on Human Research and informed consent was obtained from each subject. The second study protocol was approved by the institutional review board of the University of Michigan.

Participant Follow-Up: Study subjects have been informed to check our Web site's bibliography for publications.

\section{REFERENCES}

1. Fishman A, Martinez F, Naunheim K, Piantadosi S, Wise R, Ries A, Weinmann G, Wood DE; National Emphysema Treatment Trial Research Group. A randomized trial comparing lung-volume-reduction surgery with medical therapy for severe emphysema. N Engl J Med. 2003;348(21): 2059-73. [PMID: 12759479]

DOI:10.1056/NEJMoa030287

2. Martinez FJ, Foster G, Curtis JL, Criner G, Weinmann G, Fishman A, DeCamp MM, Benditt J, Sciurba F, Make B, Mohsenifar Z, Diaz P, Hoffman E, Wise R; NETT Research Group. Predictors of mortality in patients with emphysema and severe airflow obstruction. Am J Respir Crit Care Med. 2006;173(12):1326-34. [PMID: 16543549]

DOI:10.1164/rccm.200510-1677OC

3. Pitta F, Troosters T, Spruit MA, Probst VS, Decramer M, Gosselink R. Characteristics of physical activities in daily life in chronic obstructive pulmonary disease. Am J Respir 
Crit Care Med. 2005;171(9):972-77. [PMID: 15665324$]$ DOI:10.1164/rccm.200407-855OC

4. Schönhofer B, Ardes P, Geibel M, Köhler D, Jones PW. Evaluation of a movement detector to measure daily activity in patients with chronic lung disease. Eur Respir J. 1997;10(12):2814-19. [PMID: 9493666]

DOI:10.1183/09031936.97.10122814

5. Garcia-Aymerich J, Lange P, Benet M, Schnohr P, Antó JM. Regular physical activity reduces hospital admission and mortality in chronic obstructive pulmonary disease: A population based cohort study. Thorax. 2006;61(9):772-78. [PMID: 16738033] DOI:10.1136/thx.2006.060145

6. Watz H, Waschki B, Boehme C, Claussen M, Meyer T, Magnussen $\mathrm{H}$. Extrapulmonary effects of chronic obstructive pulmonary disease on physical activity: A cross-sectional study. Am J Respir Crit Care Med. 2008;177(7):743-51. [PMID: 18048807] DOI:10.1164/rccm.200707-10110C

7. Walker PP, Burnett A, Flavahan PW, Calverley PM. Lower limb activity and its determinants in COPD. Thorax. 2008; 63(8):683-89. [PMID: 18487318]

DOI:10.1136/thx.2007.087130

8. Project PIAL. Demographics of internet users [Internet]. Washington (DC): Pew Internet; 2010 Jan 6 [2010 Apr 14]. Available from: http://www.pewinternet.org/StaticPages/Trend-Data/Whos-Online.aspx/.

9. Horrigan J. Why we don't know enough about broadband in the U.S. [Internet]. Washington (DC): Pew Internet; 2007. Available from: http://www.pewinternet.org/Reports/2007/Why-WeDont-Know-Enough-About-Broadband-in-the-US.aspx/.

10. Tu HT, Cohen GR. Striking jump in consumers seeking health care information. Track Rep. 2008;20:1-8. [PMID: 18770913]

11. Nguyen HQ, Carrieri-Kohlman V, Rankin SH, Slaughter R, Stulbarg MS. Is internet-based support for dyspnea selfmanagement in patients with chronic obstructive pulmonary disease possible? Heart Lung. 2005;34(1):51-62. [PMID: 15647734] DOI:10.1016/j.hrtlng.2004.06.005

12. Nguyen HQ, Donesky-Cuenco D, Wolpin S, Reinke LF, Benditt JO, Paul SM, Carrieri-Kohlman V. Randomized controlled trial of an internet-based versus face-to-face dyspnea self-management program for patients with chronic obstructive pulmonary disease: Pilot study. J Med internet Res. 2008;10:e9. [PMID: 18417444] DOI:10.2196/jmir.990

13. Richardson CR, Newton TL, Abraham JJ, Sen A, Jimbo M, Swartz AM. A meta-analysis of pedometer-based walking interventions and weight loss. Ann Fam Med. 2008;6(1): 69-77. [PMID: 18195317]

DOI:10.1370/afm.761
14. Bravata DM, Smith-Spangler C, Sundaram V, Gienger AL, Lin N, Lewis R, Stave CD, Olkin I, Sirard JR. Using pedometers to increase physical activity and improve health: A systematic review. JAMA. 2007;298(19):2296-2304.

[PMID: 18029834]

DOI:10.1001/jama.298.19.2296

15. Richardson CR, Mehari KS, McIntyre LG, Janney AW, Fortlage LA, Sen A, Strecher VJ, Piette JD. A randomized trial comparing structured and lifestyle goals in an internetmediated walking program for people with type 2 diabetes. Int J Behav Nutr Phys Act. 2007;4:59. [PMID: 18021411] DOI:10.1186/1479-5868-4-59

16. Holbrook EA, Barreira TV, Kang M. Validity and reliability of Omron pedometers for prescribed and self-paced walking. Med Sci Sports Exerc. 2009;41(3):670-74.

[PMID: 19204582]

DOI:10.1249/MSS.0b013e3181886095

17. Hasson RE, Haller J, Pober DM, Staudenmayer J, Freedson PS. Validity of the Omron HJ-112 pedometer during treadmill walking. Med Sci Sports Exerc. 2009;41(4):805-9.

[PMID: 19276853]

DOI:10.1249/MSS.0b013e31818d9fc2

18. Richardson CR, Janney AW, Buis LR, Hess ML, Fortlage LA, Resnick PJ, Zikmund-Fisher BJ, Strecher VJ, Piette JD. Online community increases retention in an internetmediated walking program. North American Primary Care Research Group 2008 [Abstract].

19. Cameron LD, Leventhal H, editors. The self-regulation of health and illness behavior. London (UK): Routledge; 2003.

20. Vancouver JB, Day DV. Industrial and organizational research on self-regulation: From constructs to applications. Appl Psychol. 2005;54:155-85.

DOI:10.1111/j.1464-0597.2005.00202.x

21. Rabe KF, Hurd S, Anzueto A, Barnes PJ, Buist SA, Calverley P, Fukuchi Y, Jenkins C, Rodriguez-Roisin R, Van Weel C, Zielinski J; Global Initiative for Chronic Obstructive Lung Disease. Global strategy for the diagnosis, management, and prevention of chronic obstructive pulmonary disease: GOLD executive summary. Am J Respir Crit Care Med. 2007;176(6):532-55. [PMID: 17507545]

DOI:10.1164/rccm.200703-456SO

22. Nguyen HQ, Steele B, Benditt JO. Use of accelerometers to characterize physical activity patterns with COPD exacerbations. Int J Chron Obstruct Pulmon Dis. 2006;1(4):455-60. [PMID: 18044101] DOI:10.2147/copd.2006.1.4.455

23. Steele BG, Belza B, Cain KC, Coppersmith J, Lakshminarayan S, Howard J, Haselkorn JK. A randomized clinical trial of an activity and exercise adherence intervention in chronic pulmonary disease. Arch Phys Med Rehabil. 2008; 89(3):404-12. [PMID: 18295615] DOI:10.1016/j.apmr.2007.11.003 
24. Pitta F, Troosters T, Spruit MA, Decramer M, Gosselink R. Activity monitoring for assessment of physical activities in daily life in patients with chronic obstructive pulmonary disease. Arch Phys Med Rehabil. 2005;86(10):1979-85.

[PMID: 16213242] DOI:10.1016/j.apmr.2005.04.016

25. Pitta F, Troosters T, Probst VS, Langer D, Decramer M, Gosselink R. Are patients with COPD more active after pulmonary rehabilitation? Chest. 2008;134(2):273-80. [PMID: 18403667] DOI:10.1378/chest.07-2655

26. Patel SA, Benzo RP, Slivka WA, Sciurba FC. Activity monitoring and energy expenditure in COPD patients: A validation study. COPD. 2007;4(2):107-12. [PMID: 17530503] DOI:10.1080/15412550701246658

27. Moy ML, Garshick E, Matthess KR, Lew R, Reilly JJ. Accuracy of a uniaxial accelerometer in chronic obstructive pulmonary disease. J Rehabil Res Dev. 2008:45(4); 611-17. [PMID: 18712646$]$ DOI:10.1682/JRRD.2007.09.0147

28. Storti KL, Pettee KK, Brach JS, Talkowski JB, Richardson CR, Kriska AM. Gait speed and step-count monitor accuracy in community-dwelling older adults. Med Sci Sports Exerc. 2008;40(1):59-64. [PMID: 18091020]
29. Goodrich DE, Larkin AR, Lowery JC, Holleman RG, Richardson CR. Adverse events among high-risk participants in a home-based walking study: A descriptive study. Int J Behav Nutr Phys Act. 2007;4:20. [PMID: 17521443] DOI:10.1186/1479-5868-4-20

30. Moy ML, Matthess K, Stolzmann K, Reilly J, Garshick E. Free living physical activity in COPD: Assessment with accelerometer and activity checklist. J Rehabil Res Dev. 2009;46(2):277-86. [PMID: 19533541]

DOI:10.1682/JRRD.2008.07.0083

Submitted for publication July 8, 2009. Accepted in revised form March 2, 2010.

This article and any supplementary material should be cited as follows:

Moy ML, Janney AW, Nguyen HQ, Matthess KR, Cohen M, Garshick E, Richardson CR. Use of pedometer and Internet-mediated walking program in patients with chronic obstructive pulmonary disease. J Rehabil Res Dev. 2010; 47(5):485-96.

DOI:10.1682/JRRD.2009.07.0091 